\title{
Effect of bladder distension on dosimetry of organs at risk in computer tomography based planning of high-dose-rate intracavitary brachytherapy for cervical cancer
}

\author{
Niladri B. Patra, MBBS, MD', Kazi S. Manir, MBBS', Swapnendu Basu, MBBS, MD, DNB², Jyotirup Goswami, MBBS, MD, DNB³ \\ Apurba K. Kabasi, Msc, Dip RP, PhD', Shyamal K. Sarkar, MBBS, Dip Card, DMRT, DTMH, MD' \\ IRadiotherapy Department, Medical College and Hospitals, Kolkata, India, 2Radiotherapy Department, North Bengal Medical College \\ and Hospital, Siliguri, India, ${ }^{3 R a d i o t h e r a p y ~ D e p a r t m e n t, ~ W e s t B a n k ~ H o s p i t a l, ~ H o w r a h, ~ I n d i a ~}$
}

\begin{abstract}
Purpose: Distension and shape of urinary bladder may vary during intracavitary brachytherapy (ICBT) for cervical cancer, significantly affecting doses to bladder, rectum, sigmoid colon and small intestine and consequently late radiation toxicities. This study is to evaluate the effects of different fixed volume bladder distention on dosimetry, assessed by three dimensional image based planning, in different organs at risk during the treatment of cervical cancer with ICBT.

Material and methods: Forty seven cervical cancer patients (stage IB to IVA) were qualified for ICBT following external beam radiotherapy. Urinary bladder was distended with different volumes of normal saline instilled by a Foley's catheter. Planning CT scans were performed after insertion of applicators and three dimensional treatment planning was done on Brachyvision ${ }^{\circledR}$ treatment planning system (Varian Medical Systems, Palo Alto, CA). Dose volume histograms were analyzed. Bladder, rectum, sigmoid colon and small intestine doses were collected for individual plans and compared, based on the amount of bladder filling.

Results: Mean dose to the bladder significantly decreased with increased bladder filling. However, doses to the small volumes $(0.1 \mathrm{cc}, 1 \mathrm{cc}, 2 \mathrm{cc})$ which are relevant for brachytherapy, did not change significantly with bladder filling for bladder, rectum or sigmoid colon. Nevertheless, all dose values of small intestine are decreased significantly with bladder filling.

Conclusions: Bladder distension has no significant effect on doses received during brachytherapy by relevant volumes of bladder, rectum and sigmoid colon except intestine where values are decreased with bladder distension. A larger study with clinical correlation of late toxicities is essential for proper evaluation of this strategy.
\end{abstract}

Key words: bladder distension, cervical cancer, dosimetric comparison, intracavitary brachytherapy.

\section{Purpose}

Intracavitary brachytherapy (ICBT), in conjunction with external beam radiation (EBRT) and chemotherapy, is the standard of care in the curative management of locally advanced cervical cancer [1]. While cure rates for early cervical cancer with combinations of EBRT and ICBT are excellent, the unpredictable nature of serious morbidity of the bladder and rectum remains a serious problem. A successful treatment includes not only an improvement on tumor control, but also a reduction in treatment-related complications. It has been documented in the medical literature that there is a linear correlation between complications and total dose to the bladder and rectum [2,3]. Clinically significant consequences of irradiation of the urinary bladder in ICBT for cervical cancer have been well recognized [4]. Shape and volume of bladder during ICBT may affect dosimetric patterns of bladder, rectum and sigmoid colon. Evacuation of bladder by Foley's catheter is a common practice in ICBT, but even so, residual volume of urine is still seen on three dimensional (3D) imaging. Non-contiguous high dose areas especially in lateral horns of bladders are a major factor of dose heterogeneity of bladder [5]. It may be assumed that 
bladder tone may affect bladder shape by influencing dose distribution. Parity which influences bladder tone may be confounding factor for bladder volume-dose linear relationship. In 1981, Pilepich et al. found that by maintaining a good residual bladder volume radiation exposure to a large part of the bladder was reduced significantly [6]. Bladder distension also affects dose distribution of rectum and sigmoid colon as distended bladder shifts the rectum and sigmoid colon. Cengiz et al. did not found any significant differences in the dose distributions between an empty or full bladder. But bladder fullness significantly affected the dose to the small intestine, rectum, and sigmoid colon [7].

This study aims to evaluate the effects of bladder distension on dosimetry, assessed by 3D image based planning techniques, in bladder, rectum, sigmoid colon and small intestine in cervical cancer patients during brachytherapy, and also to search for any other factor influencing the scenario. In this study we have analyzed the potential effects on dosimetry while the clinical correlation will be discussed at a later time.

\section{Material and methods}

The study included forty seven patients of cervical cancer treated in our institute between 2009 and 2011. All patients with pathologically proved cervical cancer (stage IB to IVA) who had given a written consent were included in the study. Age below 18 years or more than 70 years, patients having pregnancy, or prior exposure to radiation therapy due to any other reason were excluded from the study. All patients were treated with EBRT (Theratron $780 C^{\circledR}$, Theratronics International, Kanata, Ontario, Canada) to the whole pelvis ( $50 \mathrm{~Gy}$ in 25 fractions using four field box technique). Concurrent chemoradiotherapy was given to patients with bulky tumors or $\geq$ IB stage. After completion of EBRT, patients were evaluated for eligibility for receiving brachytherapy. Intracavitary brachytherapy was done under sedation using CT compatible applicators (Manchester type

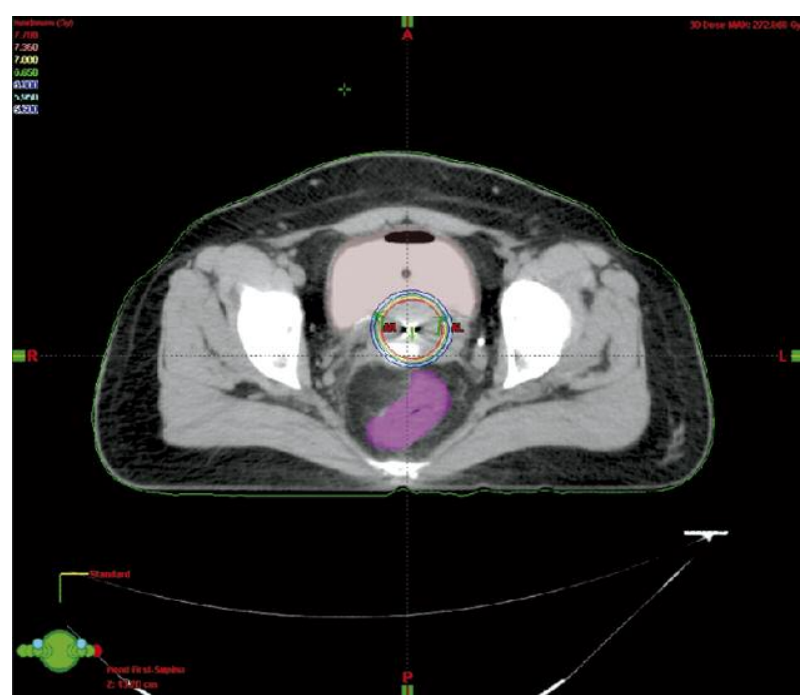

Fig. 1. Image of axial section of computer tomography showing isodose curves during intracavitary brachytherapy of cervical cancer patient or Fletcher-Suit type). Soon after first intracavitary insertion patients were sent for planning CT scan (BrillianceCT-16 ${ }^{\circledR}$ slice with Accusim Virtual simulation, Philips Health Care Solutions, DA Best, The Netherlands). CT scans were obtained from the level of the obturator foramen to at least $1 \mathrm{~cm}$ beyond the tandem tip in the cephalad direction with $3 \mathrm{~mm}$ slice thickness. In thirty six patients, just before CT scan, we instilled different fixed volumes of normal saline in urinary bladder by Foley's catheter, followed by clamping of the catheter while the rest were scanned with empty bladder with continuous drainage by Foley's catheter. Patients were stratified into 4 different groups: group A - empty bladder group (defined as no extra saline or contrast material given after Foley's catheter insertion, gentle evacuation of bladder done by Foley's catheter); group B (up to $40 \mathrm{cc}$ instillation); group C (41-80 cc instillation); group D (81 cc and above instillation). The CT data was transferred to the treatment-planning system (Brachyvision TPS ${ }^{\circledR}$, Eclipse, Varian Medical Systems, Palo Alto CA, USA) computer. Contrast material was mixed with saline to define the bladder wall; barium was instilled into the sigmoid and rectum. The external contour of the bladder, rectum, sigmoid colon, and small bowel in the pelvis were delineated on each CT slice. In this study, the rectum was delineated from the anal verge to the recto-sigmoid junction, and the sigmoid colon was defined as the large bowel above the rectum to the level of the lumbosacral interspace. The bowel excluding the sigmoid colon and rectum in the pelvis was defined as small bowel. Rectal contrast helped to define the recto-sigmoid junction. External contour of whole bladder was taken for contouring not the wall only. The reason for contouring the whole organ is a possibility of thinning of walls due to bladder distension leading to changes in DVH parameters of small volume doses if only wall is taken for contouring. The prescribed dose was either $7 \mathrm{~Gy} \times 3$ fractions or $9 \mathrm{~Gy}$ $\times 2$ fractions of $\mathrm{HDR}$ at point A. Point A was defined as $2 \mathrm{~cm}$ superior of the upper surface in the middle of the ovoid and $2 \mathrm{~cm}$ lateral to the uterine tandem (same coronal plane) on

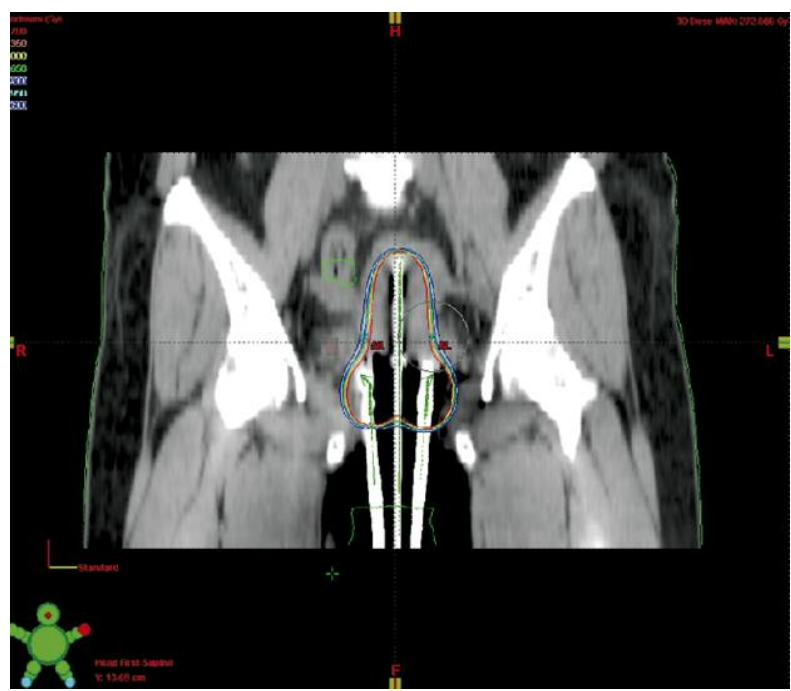

Fig. 2. Image of coronal section of computer tomography showing isodose curves during intracavitary brachytherapy of cervical cancer patient 


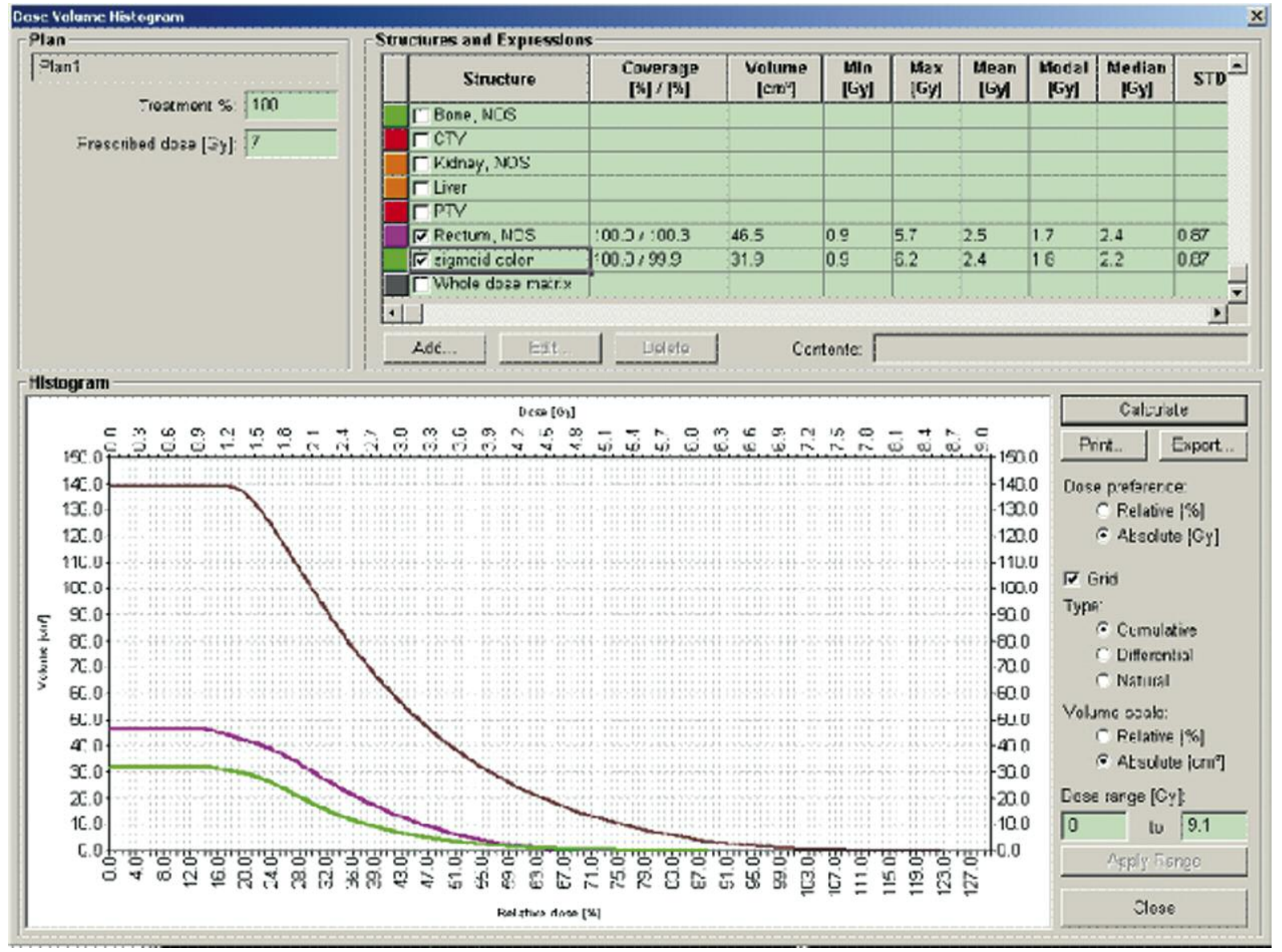

Fig. 3. Image of dose volume histogram showing dose distribution pattern over cervix, bladder, rectum, sigmoid colon during intracavitary brachytherapy of cervical cancer

reconstructed CT image [8]. 3D manual optimization of the HDR plans were done, if required, to achieve acceptable doses to Point A, bladder, rectum and sigmoid colon. Patient were then treated by the GammaMedplus HDR ${ }^{\circledR}$ afterloader unit (Varian Medical Systems, Palo Alto, CA, USA) using Iridium-192 (Figs. 1, 2). Different doses and dose volume data were assessed for the bladder, rectum and sigmoid colon from the cumulative dose volume histograms (DVH). These include doses to $0.1 \mathrm{cc}, 1 \mathrm{cc}$ and $2 \mathrm{cc}$ volumes of each of the structures, as well as the maximum and mean doses (Fig. 3). Statistical analysis was done using the SPSS software (version 19.0). Dose volume data from different groups were compared using independent $t$ sample test, multivariate regression model (ANOVA, post hoc test). A $p$-value of less than 0.05 was considered statistically significant. Adjustment for potential confounders (including parity, tumor stages, and type of applicator used) was performed in multiple linear regression models.

\section{Results}

Among all forty seven patients, maximum population was in group $C(n=18,38 \%)$ and minimum patient population was observed in group $\mathrm{D}(n=6,12 \%)$. Most common stage was stage IIB $(n=21,44 \%)$ followed by stage IIIB $(n=10,21 \%)$.
Most common parity was P2+0 $(n=13,27.7 \%)$. Majority of patients were treated with Manchester type of applicator $(n=28,59.6 \%)$ (Table 1). Median value of point A dose in all groups was $6.99 \mathrm{~Gy}$; mean value of point A dose was 7.028

\section{Table 1. Descripted statistics}

\begin{tabular}{llcc} 
Population & & N & Percentage \\
\hline Total 47 & Group A* & 12 & 25 \\
\cline { 2 - 4 } & Group B & 11 & 23.4 \\
\cline { 2 - 4 } & Group C & 18 & 38.3 \\
\cline { 2 - 4 } Stage & Group D & 6 & 12.8 \\
\cline { 2 - 4 } & IIA & 7 & 14.9 \\
\cline { 2 - 4 } & IIB & 4 & 8.5 \\
\cline { 2 - 4 } & IIIA & 10 & 44.7 \\
\cline { 2 - 4 } & IIIB & 0 & 10.6 \\
\cline { 2 - 4 } & IVA & 28 & 0 \\
\hline Applicator & Fletcher suit type & 19 & 40.4 \\
\cline { 2 - 4 } & Manchester type & 28.4
\end{tabular}

${ }^{*}$ Group A: empty bladder; group B: up to 40 cc; group C: $41-80$ cc; group D: $>81 \mathrm{CC}$ 
\pm 0.67 Gy (Table 2). Detailed dose patterns of bladder doses (maximum dose, mean dose, $0.1 \mathrm{ml}$ dose, $1 \mathrm{ml}$ dose, $2 \mathrm{ml}$ dose) are described in Table 3 . On post hoc test analysis and multivariate analysis during multiple comparisons among each groups we found that mean dose of bladder

Table 2. Point A dose in different study groups

\begin{tabular}{ccc} 
Group & $\begin{array}{c}\text { Mean dose } \\
\text { (Gy) }\end{array}$ & $\begin{array}{c}\text { Mean of percentage } \\
\text { of prescribed dose }\end{array}$ \\
\hline A & $7.034 \pm 0.35$ & $99.3 \pm 2.05$ \\
\hline$B$ & $7.040 \pm 0.74$ & $90 \pm 10$ \\
\hline C & $6.9 \pm 0.84$ & $99.0 \pm 4.0$ \\
\hline$D$ & $7.025 \pm 0.75$ & $97.67 \pm 2.3$
\end{tabular}

was significantly decreased in group $\mathrm{D}$ in comparison to group A $(p=0.001)$ and also with group $\mathrm{B}(p=0.038)$ (Table 4). Mean values of mean doses of bladder were 3.2 Gy in group A, 2.9 Gy in group B, 2.8 Gy in group C and 2.2 Gy in group $\mathrm{D}$. These findings were also validated by Kruskal Wallis test (Monte Carlo significance was 0.02) and Mann Whitney $U$ test. Description of different dose distribution parameters of rectum and sigmoid colon are given in Table 5 and Table 6.

In the same way we compared the different dose distribution patterns (maximum dose, mean dose, $0.1 \mathrm{cc}, 1 \mathrm{cc}$ and 2 cc volume dose) of rectum and sigmoid colon by using multivariate analysis, post hoc test and Kruskal Wallis test. Dose distribution data was not normally distributed. There were statistically insignificant minute changes in dose distribution

Table 3. Comparative dose distrbution pattern in bladder in different groups

\begin{tabular}{|c|c|c|c|c|c|}
\hline $\begin{array}{l}\text { Mean value Gy } \\
\text { (\% of prescribed } \\
\text { dose ) }\end{array}$ & Group A & Group B & Group C & Group D & $\begin{array}{c}P \text { value } \\
\text { (ANOVA test) }\end{array}$ \\
\hline Maximum dose & $\begin{array}{l}10.5 \pm 2.8 \\
(148 \pm 42 \%)\end{array}$ & $\begin{array}{c}9.1 \pm 2.6 \\
(120 \pm 37 \%)\end{array}$ & $\begin{array}{c}9.7 \pm 1.6 \\
(148 \pm 30 \%)\end{array}$ & $\begin{array}{l}10.9 \pm 3 \\
(159 \pm 35 \%)\end{array}$ & $0.353(>0.05)$ \\
\hline Mean dose & $\begin{array}{l}3.2 \pm 0.63 \\
(45 \pm 6.7 \%)\end{array}$ & $\begin{array}{l}2.9 \pm 0.61 \\
(39 \pm 7 \%)\end{array}$ & $\begin{array}{l}2.8 \pm 0.37 \\
40 \pm 8 \%\end{array}$ & $\begin{array}{l}2.2 \pm 0.37 \\
(32 \pm 7 \%)\end{array}$ & $0.002(<0.05)^{\#}$ \\
\hline 0.1 cc dose* & $\begin{array}{l}8.66 \pm 0.8 \\
(124 \pm 3 \%)\end{array}$ & $\begin{array}{c}9.1 \pm 2.5 \\
(102.6 \pm 15 \%)\end{array}$ & $\begin{array}{c}8.8 \pm 1.6 \\
(120 \pm 14 \%)\end{array}$ & $\begin{array}{c}8.9 \pm 2 \\
(130 \pm 14 \%)\end{array}$ & $0.083(>0.05)$ \\
\hline 1 cc dose & $\begin{array}{c}7.5 \pm 1.02 \\
(105 \pm 19 \%)\end{array}$ & $\begin{array}{l}6.5 \pm 1.3 \\
(89 \pm 16 \%)\end{array}$ & $\begin{array}{c}7.3 \pm 1 \\
(109 \pm 15 \%)\end{array}$ & $\begin{array}{c}7.3 \pm 1.6 \\
(106 \pm 18 \%)\end{array}$ & $0.23(>0.05)$ \\
\hline 2 cc dose & $\begin{array}{l}6.8 \pm 1.8 \\
(95 \pm 16.8 \%)\end{array}$ & $\begin{array}{c}6.0 \pm 1.1 \\
(82.0 \pm 15 \%)\end{array}$ & $\begin{array}{l}6.7 \pm 1 \\
(101 \pm 16 \%)\end{array}$ & $\begin{array}{l}6.6 \pm 1.3 \\
(96 \pm 22 \%)\end{array}$ & $0.281(>0.05)$ \\
\hline
\end{tabular}

*0.1 cc dose: minimum dose to the maximally exposed $0.1 \mathrm{cc}$ volume extrapolated from; \#statistically significant

Table 4. Bladder mean dose distribution on multiple comparison (post hoc test)

\begin{tabular}{ccccccc} 
Group 1 & Group 2 & $\begin{array}{c}\text { Mean difference } \\
\text { (group 1 - group 2) }\end{array}$ & Standard error & Significance & \multicolumn{2}{c}{ 95\% confidence limit } \\
\hline D & A & -1.05 & 0.269 & $0.001^{*}$ & -1.76 & -0.33 \\
\hline & B & -0.75 & 0.26 & $0.038^{*}$ & -1.48 & -0.02 \\
\hline & C & -0.59 & 0.24 & 0.11 & -0.8 & 1.2
\end{tabular}

${ }^{*} p$ value $<0.05$ is statistically significant

Table 5. Comparative dose distribution pattern in rectum among different groups

\begin{tabular}{lccccc}
$\begin{array}{l}\text { Mean value Gy } \\
\text { (\% of prescribed } \\
\text { dose) }\end{array}$ & Group A & Group B & Group C & Group D & $\begin{array}{c}P \text { value } \\
\text { (ANOVA test) }\end{array}$ \\
\hline Maximum dose & $6.8 \pm 2.5$ & $7.6 \pm 2.7$ & $7.9 \pm 2.9$ & $8.15 \pm 0.48$ & $0.69(>0.05)$ \\
& $(97 \pm 30 \%)$ & $(103 \pm 40 \%)$ & $(116 \pm 40 \%)$ & $(117 \pm 15 \%)$ & \\
\hline Mean dose & $2.5 \pm 0.59$ & $2.8 \pm 0.48$ & $2.7 \pm 0.62$ & $2.5 \pm 0.68$ & $0.704(>0.05)$ \\
& $(36 \pm 9 \%)$ & $(36 \pm 6 \%)$ & $(40 \pm 8 \%)$ & $(35 \pm 9 \%)$ & $0.267(>0.05)$ \\
\hline 0.1 cc dose* & $6.4 \pm 1.9$ & $6.9 \pm 2.5$ & $6.7 \pm 2$ & $6.7 \pm 1.2$ & $(94 \pm 21 \%)$ \\
& $(124 \pm 31 \%)$ & $(86.8 \pm 30 \%)$ & $(101 \pm 25 \%)$ & $4.8 \pm 0.99$ & $0.599(>0.05)$ \\
\hline 1 cc dose & $4.7 \pm 1.5$ & $5.3 \pm 1.8$ & $5.5 \pm 1.5$ & $(70 \pm 16 \%)$ & \\
\hline 2 cc dose & $(66 \pm 21 \%)$ & $(68 \pm 9 \%)$ & $(81 \pm 18 \%)$ & $4.3 \pm 0.79$ & $0.482(>0.05)$ \\
& $4.4 \pm 1.3$ & $4.9 \pm 1.4$ & $4.9 \pm 1.2$ & $(73.6 \pm 15 \%)$ &
\end{tabular}

${ }^{\star} 0.1 \mathrm{cc}$ dose: minimum dose to the maximally exposed $0.1 \mathrm{cc}$ volume extrapolated from dose volume histogram 
Table 6. Comparative dose distribution pattern in sigmoid colon among different groups

\begin{tabular}{|c|c|c|c|c|c|}
\hline $\begin{array}{l}\text { Mean value Gy } \\
\text { (\% of prescribed } \\
\text { dose) }\end{array}$ & Group A & Group B & Group C & Group D & $\begin{array}{c}P \text { value } \\
\text { (ANOVA test) }\end{array}$ \\
\hline Maximum dose & $\begin{array}{c}8.5 \pm 1.2 \\
(119 \pm 44 \%)\end{array}$ & $\begin{array}{c}11.9 \pm 4.3 \\
(162 \pm 31 \%)\end{array}$ & $\begin{array}{c}9.6 \pm 5 \\
(140 \pm 70 \%)\end{array}$ & $\begin{array}{c}7.4 \pm 1.9 \\
(102 \pm 33 \%)\end{array}$ & $0.304(>0.05)$ \\
\hline Mean dose & $\begin{array}{l}2.7 \pm 0.8 \\
(38 \pm 11 \%)\end{array}$ & $\begin{array}{l}3.3 \pm 0.95 \\
(45 \pm 13 \%)\end{array}$ & $\begin{array}{c}3.1 \pm 1.2 \\
(46 \pm 15 \%)\end{array}$ & $\begin{array}{c}2.9 \pm 1.2 \\
(41.7 \pm 13 \%)\end{array}$ & $0.535(>0.05)$ \\
\hline 0.1 cc dose $^{*}$ & $\begin{array}{c}7.1 \pm 2.4 \\
(107 \pm 38 \%)\end{array}$ & $\begin{array}{c}8.3 \pm 3.2 \\
(103 \pm 32 \%)\end{array}$ & $\begin{array}{c}6.7 \pm 2 \\
(101 \pm 25 \%)\end{array}$ & $\begin{array}{c}6.4 \pm 2.8 \\
(90.4 \pm 34 \%)\end{array}$ & $0.647(>0.05)$ \\
\hline 1 cc dose & $\begin{array}{l}5.2 \pm 1.9 \\
(71 \pm 26 \%)\end{array}$ & $\begin{array}{l}6.7 \pm 2.2 \\
(91 \pm 33 \%)\end{array}$ & $\begin{array}{l}5.5 \pm 2.3 \\
(76 \pm 11 \%)\end{array}$ & $\begin{array}{l}4.8 \pm 2.5 \\
(62 \pm 24 \%)\end{array}$ & $0.261(>0.05)$ \\
\hline 2 cc dose & $\begin{array}{l}4.5 \pm 1.5 \\
(63 \pm 22 \%)\end{array}$ & $\begin{array}{c}5.8 \pm 1.6 \\
(77.0 \pm 24 \%)\end{array}$ & $\begin{array}{c}4.6 \pm 2 \\
(69.5 \pm 23 \%)\end{array}$ & $\begin{array}{c}4.3 \pm 2.2 \\
(59.4 \pm 23 \%)\end{array}$ & $0.245(>0.05)$ \\
\hline
\end{tabular}

${ }^{*} 0.1 \mathrm{cc}$ dose: minimum dose to the maximally exposed $0.1 \mathrm{cc}$ volume extrapolated from dose volume histogram

Table 7. Comparative dose distribution pattern in small intestine between group A and D (independent $t$ sample test)

\begin{tabular}{|c|c|c|c|c|c|c|c|c|}
\hline Dose & Group & $\begin{array}{c}\text { Mean } \\
\text { (Gy) }\end{array}$ & $\begin{array}{c}\text { Mean } \\
(\%)^{\#}\end{array}$ & $\begin{array}{c}\text { Standard } \\
\text { deviation } \\
\text { (Gy) }\end{array}$ & $\begin{array}{c}\text { Standard } \\
\text { deviation } \\
(\%)^{\#}\end{array}$ & $\begin{array}{l}\text { Standard } \\
\text { error mean } \\
(G y)\end{array}$ & $\begin{array}{l}\text { Standard } \\
\text { error mean } \\
(\%)^{\#}\end{array}$ & $P$ value ${ }^{\star \star}$ \\
\hline \multirow{2}{*}{ Max } & $A$ & 5.45 & 79.30 & 0.07 & 0.98 & 0.05 & 0.70 & \multirow{2}{*}{0.046} \\
\hline & $D$ & 3.66 & 50.66 & 0.70 & 12.63 & 0.40 & 7.26 & \\
\hline \multirow{2}{*}{ Mean } & $A$ & 1.25 & 17.85 & 0.21 & 3.04 & 0.15 & 2.15 & \multirow{2}{*}{0.401} \\
\hline & D & 0.90 & 12.36 & 0.26 & 4.09 & 0.15 & 2.36 & \\
\hline \multirow{2}{*}{$0.1 c c^{\star}$} & $A$ & 4.86 & 65.95 & 0.14 & 3.04 & 0.10 & 2.15 & \multirow{2}{*}{0.042} \\
\hline & $D$ & 2.83 & 43.16 & 0.75 & 17.29 & 0.43 & 9.98 & \\
\hline \multirow{2}{*}{$1 \mathrm{cc}$} & $A$ & 3.80 & 54.45 & 0.13 & 2.05 & 0.09 & 1.45 & \multirow{2}{*}{0.38} \\
\hline & D & 2.18 & 31.83 & 0.57 & 12.89 & 0.33 & 7.44 & \\
\hline \multirow{2}{*}{$2 c c$} & $A$ & 3.50 & 49.65 & 0.00 & 0.49 & 0.0 & 0.35 & \multirow{2}{*}{0.49} \\
\hline & $D$ & 1.97 & 29.03 & 0.55 & 11.67 & 0.32 & 6.73 & \\
\hline
\end{tabular}

*0.1 cc dose: minimum dose to the maximally exposed $0.1 \mathrm{cc}$ volume extrapolated from dose volume histogram; ** $p$ value < 0.05 significant; \#\% of prescribed dose

Table 8. Relation of parity and bladder dose (ANOVA test result corrected model using parity as co variable)

\begin{tabular}{lcccc}
$\begin{array}{l}\text { Depended variable } \\
\text { (mean value) }\end{array}$ & Summary of squares & Mean square & Ffactor & Significance* $^{*}$ \\
\hline Maximum dose & 50.814 & 50.814 & 10.199 & 0.003 \\
\hline Mean dose & 0.628 & 0.682 & 2.85 & 0.097 \\
\hline 0.1 cc dose & 8.725 & 10.632 & 8.12 & 0.005 \\
\hline 1 cc dose & 8.725 & 7.054 & 7.68 & 0.008 \\
\hline 2 cc dose & 10.632 & 7.045 & 6.932 & 0.12
\end{tabular}

* $p$ value $<0.05$ is statistically significant; \#minimum dose to maximally exposed 0.1 cc volume of bladder

in rectum and sigmoid colon (Tables 5 and 6). Mann Whitney $U$ test was used to compare different groups, but no statistically significant difference was found.

On analysing results of independent $t$ sample test results of the dosimetric data of small intestine we found that dose values (maximum dose, 1 cc, 2 cc doses) are significantly decreased only in group $\mathrm{D}$ in comparison to group $\mathrm{A}$. However, no statistical difference exists while comparing other groups (Table 7).

On analysing covariables such as parity, stage, applicator type (multivariate analysis) it has been found that ma- ximum dose, $0.1 \mathrm{cc}$ and $1 \mathrm{cc}$ volume doses increased with parity $(p=0.0025)$ and they were significantly correlated (Pearson correlation coefficient $=455.25)($ Table 8). But no significant change was seen 2 cc bladder, rectum and sigmoid colon dose parameters. Dose pattern changes were not influenced either by stage of the disease or applicator type. It was also evident from data analysis that in the empty bladder group (group A) there was a significant amount of urine collection was noticed even after evacuation. Mean bladder volume (contoured) from the CT images was $129.25 \pm 19.1 \mathrm{cc}$. Median value was $122.9 \mathrm{ml}$. 


\section{Discussion}

This study investigated the bladder distension effect on dosimetry in 47 patients with cervical cancer receiving ICBT. We found that bladder mean dose significantly decreases from empty bladder group to distended bladder group (3.2 Gy in group A, 2.9 Gy in group B, 2.8 Gy in group C and $2.2 \mathrm{~Gy}$ in group D). Bladder distension does not affect other dose parameters. Foleys catheterisation and evacuation of bladder is being practised from earlier days. This concept was especially beneficial for low-dose-rate (LDR) brachytherapy where the treatment time was longer. Alteration of bladder filling status and shape and position of bladder alters the relative anatomy of uterus, sigmoid colon intestinal loop and also rectum. It had been assumed that the distended bladder might shift the sigmoid colon and intestinal loop from the uterus, thereby having a sparing effect on sigmoid colon, intestinal loop and may be on rectum.

In 1981, Pilepich et al. discussed the effect of bladder distension on dosimetry in gynaecological implants. They found that by maintaining a residual vesical volume of 200-300 cc with contrast material, the radiation exposure to a large part of the bladder was reduced significantly, while only a minor displacement of the implant system was noted [6].

This concept was also validated by two studies done in this decade. Sun et al. analyzed DVH data of 20 cervical cancer patients with empty and full bladder volumes and found that there is a statistically significant association between bladder filling status and median bladder wall absorbed dose. Bladder distension can approximately reduce the median bladder wall absorbed dose by $48 \%$, and they concluded that this procedure may reduce the incidence of acute reactions and long-term complications. There was no clinical outcome data in the study [8].

Buchali et al. have studied over 29 women regarding determination of the impact of the filling status of the organs at risk (bladder and rectum) on the uterus mobility and on their integral dose distribution in radiotherapy of gynecological cancer. They have found that full bladder is an important factor for sparing dose burden for this organ, particularly if more than one third of the bladder is taken into consideration [1].

In contrast to these observations, two other studies show opposite results. Kim et al. have shown that an increase in bladder volume resulted in a significant reduction in $2 \mathrm{cc}$ bowel volume doses at the expense of an increase in $2 \mathrm{cc}$ bladder volume doses. They recommended that treatment with a distended bladder is preferable to protect the bowel. However, this study did not provide any information regarding clinical correlation of these changes [10]. Cengiz et al. have studied ten patients with empty and full bladder and found no significant difference regarding the dose distribution and target volumes between an empty or full bladder. But bladder fullness significantly affected the dose to the small intestine, rectum, and sigmoid colon [7].

Our study was intended to reevaluate these findings. In our study, there were four groups. In group A (empty bladder group) we tried gentle evacuation of bladder by Foley's catheter. But still there was a significant residual urine volumes (mean contoured volume was $129 \pm 19 \mathrm{cc}$ ).
In group D average instillation was $100 \mathrm{cc}(80-120 \mathrm{cc})$ unlike previous studies. This volume was comfortably tolerated by patients. Unlike other studies we treated all the patients with same bladder filling status as done during imaging. All the patients underwent CT imaging. No magnetic resonance imaging (MRI) was done. During contouring we took whole organ for contouring, not the wall alone. During data collection, calculation and comparison mean values of maximum, mean doses of bladder, rectum and sigmoid colon were taken as like previous studies.

We also included small volume dose values $(0.1 \mathrm{cc}, 1 \mathrm{cc}$, $2 \mathrm{cc})$ following GEC-ESTRO recommendations [5,9], as these volumes are key parameters to evaluate late toxicities. Main emphasis was given during analysis on how these small dose volume parameters were affected. During intergroup analysis we found all the dose volumes were changing in different groups, but all the changes were not statistically significant. There was no significant change in the mean value of maximum dose to bladder unlike previous studies. Only the mean value of bladder mean dose significantly decreases with increasing bladder $(p=0.001)$ distension. There were no significant changes in $0.1 \mathrm{cc}, 1 \mathrm{cc}, 2 \mathrm{cc}$ volume dose values of bladder.

Unlike previous studies changes of dose volume parameters of rectum and sigmoid colon were not significant. But in case of small intestine, the analyzed dose parameters (maximum dose, $0.1 \mathrm{ml}$ dose, $1 \mathrm{ml}$ dose and $2 \mathrm{cc}$ dose) are significantly decreased on bladder distension. In a similar prospective study, Kim et al. found an increase in bladder volume resulted in a significant reduction in bowel $2 \mathrm{cc}$ dose values at the expense of an increase in bladder $2 \mathrm{cc}$ and mean dose values. They conclude that the treatment with a distended bladder is preferable to protect the bowel. These results corroborate with the results of previous study by Kim et al. [10]. Our study results partially corroborate with these findings.

On analyzing the confounding factors it was evident that weak positive correlation exists between parity and mean values of bladder maximum dose (average $p=0.0025$ ). We assumed that high parity might have influenced bladder tone and increase the high dose areas of lateral horns, which was evident on comparing the planning CT images. Analyzing all these changes, though there was decrease in bladder mean dose in distended bladder group, the result was not encouraging, as there was no change of $1 \mathrm{cc}$ and $2 \mathrm{cc}$ bladder volume doses. But interestingly, our results revealed decrease in all small intestine volume dose parameters in this group. This bladder distension protocol may be a good strategy to prevent small intestine toxicity.

We recognized some limitations of the study also. Sample size was small $(n=47)$. Contouring of bladder was sometimes difficult in CT images. The group A population had significant residual volume of urine after evacuation which may be a confounding factor, though not statistically significant $(p=0.46)$. Clinical outcomes were not evaluated in this study, the dosimetry alteration shown by the treatment planning system may not completely reflect clinical bladder complications. The sample population will remain under our clinical observation. Clinical correlation will be discussed later on after reasonable follow up period. Further 
investigation with large sample size and clinical correlation is needed.

\section{Conclusions}

There is no significant change in dosimetric parameters of bladder, rectum and sigmoid colon with bladder distention except small intestine, where the values (maximum doses, $0.1 \mathrm{cc}, 1 \mathrm{cc}$ and $2 \mathrm{cc}$ doses) are decreased on bladder distension. Mean bladder dose decreases with distension of bladder. But the small volume dose parameters $(0.1 \mathrm{cc}, 1 \mathrm{cc}$ and $2 \mathrm{cc}$ ) of bladder, rectum and sigmoid colon, which are actually important for late toxicities in ICBT patients, were unchanged. Clinical significance of these changes are unknown. A larger study with clinical correlation of late toxicities is needed to is needed to evaluate this strategy.

\section{Acknowledgements}

This study was a dosimetric study. No extra financial help was needed. We express thanks to the faculty members, residents and staffs of Department of Radiotherapy Medical College and Hospitals, Kolkata. Special thanks to Dr. Suman Mallick Consultant Radiation Oncologist, WestBank Hospital, Howrah for his cordial help for improvising concept and statistical analysis. Special thanks to Mr. Kaushik Ghosh Medical Physicist, R.G. Kar. Medical College and Hospital, Kolkata for his help.

\section{References}

1. Buchali A, Koswig S, Dinges S et al. Impact of the filling status of the bladder and rectum on their integral dose distribution and the movement of the uterus in the treatment planning of gynecological cancer. Radiother Oncol 1999; 52: 29-34.

2. Chen HC, Leung SW, Wang CJ et al. Local vaginal anesthesia during high-dose-rate intracavitary brachytherapy for cervical cancer. Int J Radiat Oncol Biol Phys 1998; 42: 541-544.

3. Montana GS, Fowler WC, Varia MA et al. Carcinoma of the cervix: Analysis of bladder and rectal radiation dose and complications. Int J Radiat Oncol Biol Phys 1989; 16: 95-100.

4. Gellrich J, Hakenberg OW, Oehlschlager S et al. Manifestation, latency and management of late urological complications after curative radiotherapy for cervical carcinoma. Onkologie 2003; 26: 334-340

5. Haie-Meder C, Potter R, Van Limbergen E et al. Recommendations from Gynaecological (GYN) GECESTRO Working Group (I): concepts and terms in 3D image based 3D treatment planning in cervix cancer brachytherapy with emphasis on MRI assessment of GTV and CTV. Radiother Oncol 2005; 74: 235-245.

6. Pilepich MV, Prasad S, Madoc-Jones H et al. Effect of bladder distension on dosimetry in gynecological implants. Radiology 1981; 140: 516-518.

7. Cengiz M, Gürdalli S, Selek U et al. Effect of Bladder Distension on Dose Distribution of Intracavitary Brachytherapy for Cervical Cancer: Three-Dimensional Computed Tomography Plan Evaluation. Int J Radiat Oncol Biol Phys 2008; 70: 464-468.

8. Sun LM, Lin H, Huang HY, et al. A prospective study to assess the bladder distension effects on dosimetry in intracavitary brachytherapy of cervical cancer via computed tomographyassisted techniques. Radiother Oncol 2005; 77: 77-82.

9. Pötter R, Haie-Meder C, Van Limbergen E et al. Recommendations from gynaecological (GYN) GEC ESTRO working group (II): concepts and terms in 3D image-based treatment planning in cervix cancer brachytherapy-3D dose volume parameters and aspects of 3D image-based anatomy, radiation physics, radiobiology. Radiother Oncol 2006; 78: 67-77.

10. Kim RY, Shen S, Lin HY et al. Effects of bladder distension on organs at risk in 3D image-based planning of intracavitary brachytherapy for cervical cancer. Int J Radiat Oncol Biol Phys 2010; 76: 485-489. 